\title{
ALGUMAS REFLEXÕES SOBRE O PAPEL DA ESCOLA DE 20. GRAU
}

\author{
José Sérgio F de CARVALHO
}

\begin{abstract}
Que se destine meu aluno à carreira militar, à eclesiática ou à advocacia pouco me importa. Antes da vocação dos pais, a natureza chama-o para a vida humana. Viver é o ofício que quero ensinar. Saindo de minhas mãos, ele não será. concordo, nem magistrado, nem soldado nem padre; será primeiramente um homem ' (Jean Jacques Rousseau).
\end{abstract}

Essa idéia de que a escola tem como papel a formação global do homem, tão bem expressa na citação de Rousseau, não é apenas um ideal de educação formulado como um princípio teórico de uma doutrina filosófica. A própria legislação brasileira o consagra como uma diretriz pedagógica, ao afirmar que a educação do 2o. grau deve ter como princípio a formação do cidadão. E é interessante notar quão pouca atenção tem sido dada a esse preceito teórico, talvez até por acreditarmos que ele é suficientemente claro e que dispensa reflexões mais detalhadas. Assim, cremos que nossa dificuldade residiria menos em compreendê-lo do que em viabilizá-lo em termos práticos, sobretudo em face da forte demanda atual no sentido de que o ensino de 20. grau seja eminentemente uma ponte para o ensino superior, assim como o de 10. grau deve fornecer as bases para o 20. grau.

Assim compreendida a especificidade da escola de 20. grau, a prioridade para a formação da cidadania, prevista em lei, cede espaço, pragmaticamente, à preparação para o vestibular e ao acesso ao ensino superior, ainda que na verdade boa parte de nossos alunos não tenha a menor chance de atingir esse grau de escolaridade. A oposição a essa visão pragmática ou utilitarista do papel social da escola de 20. grau, por outro lado, tem freqüentemente se pautado pela idéia de que à instituiçăo escolar cabe fornecer as diretrizes de um projeto político, promovendo a consciência necessária à implementação de uma nova realidade social e política, da qual os professores seriam os porta-vozes. Essa seria, portanto, a forma de recuperarmos o preceito da escola como compromisso para com a cidadania.

Gostaria de apresentar, através destas breves reflexð̃es, tanto a pertinência da máxima consagrada em lei, como o equívoco de que ela tem sido vítima, tanto no caso da transformação do 20 . grau em preparação para o vestibular, como na visão de que cabe à escola guiar as transformações políticas da sociedade, que pretensamente recuperaria sua ligação com a formação para a cidadania. Mais ainda, gostaria de mostrar como ambas as posturas têm em sua raiz o mesmo equívoco básico. E esse equívoco não se deve exclusivamente ao problema real de que a idéia de cidadania é algo vago, que necessitaria de uma explicitação mais clara se quisermos por ela nos guiar. Este equívoco tem por base, como destaca Arendt ${ }^{2}$, os ideais desenvolvidos na modernidade, sobretudo a partir do próprio Rousseau, de que a educação tem um compromisso político com o futuro, sendo a atividade pedagógica essencialmente política, assim como a atividade política seria, também ela, essencialmente pedagógica.

A idéia de que toda pedagogia é política, assim como toda atividade política é pedagógica ganhou considerável espaço em nossa sociedade, sobretudo a partir dos anos 60 , uma vez que o voto expressão simbólica máxima da cidadania - era restrito aos alfabetizados. Nada melhor para expressar essa equivalência entre as atividades políticas de um professor e caráter pedagógico da ação política dos cidadãos

Faculdade de Educação, Universidade de São Paulo. 
do que o slogan difundido e consagrado de que todo educador é um educando e todo educando é um educador ${ }^{3}$ No entanto, como nos alerta Arendt, com extrema lucidez:

às crianças que se quer educar para que sejam cidadãos de um amanhã utópico é negado, de fato, seu próprio futuro no organismo político, pois, do ponto de vista dos mais novos, o que quer que o mundo adulto possa propor de novo é necessariamente mais velho que eles mesmos. Pertence à própria natureza da condição humana o fato de que cada geração se transforma em um mundo antigo, de tal modo que preparar uma nova geração para um mundo novo só pode significar o desejo de arrancar das mãos dos recém-chegados sua própria oportunidade em face ao novo (1972, p.226).

Assim, preparar o futuro pelas mãos de nossos alunos, seja qual for o futuro vislumbrado: uma sociedade sem classes, uma utopia tecnológica pós-moderna ou outra qualquer, significa transferir para eles responsabilidades que são nossas e retirar deles a responsabilidade, que lhes é própria, pelos caminhos do mundo de amanhã. E simultaneamente significa também que não assumimos nossas responsabilidades, posto que, gostemos ou não deste mundo ao qual pertencemos, por ele somos coletiva e historicamente responsáveis:

o educador está em relação ao jovem como representante de um mundo pelo qual deve assumir responsabilidade, embora não o tenha feito e ainda que secreta ou abertamente possa querer que ele fosse diferente do que é. Essa responsabilidade não é imposta arbitrariamente aos educadores; ela está implícita no fato de que os jovens são introduzidos por adultos em um mundo em contínua mudança. Qualquer pessoa que se recuse a assumir a responsabilidade coletiva pelo mundo não deveria ter crianças e é preciso proibi-la de tomar parte em sua educação (Arendt, 1972, p.239).

Essa insistente recusa em apresentar às gerações mais novas o mundo em que elas serão por nós inseridas, tal como ele tem sido e é, só pode significar nosso desprezo e mal-estar pelo mundo presente. Comportamo-nos em face do mundo atual como seres que têm saudade do futuro e vergonha do passado. Mas somos, em face de nossos alunos, seres do passado e do presente, não do futuro. A bem da verdade, fazer da educação simplesmente um instrumento para o futuro - seja através das utopias que lhes legamos como se estas fossem legítimas escolhas deles ou ainda, numa perspectiva individualista, quando justificamos a educação como uma ponte, por vezes um mal necessário, para um futuro econômico individual melhor, é negar à educação seu papel mais relevante, expresso na idéia, que insisto tem sido mal compreendida, de uma preparação para a cidadania, ou seja para a vida ativa no mundo dos homens.

Se no plano coletivo preparar o futuro a partir de nossos sonhos passados é, no mínimo, ilegítimo, no plano individual é, pelo menos, em grande medida inútil. Em um mundo que se enriquece continuamente com novas técnicas, novas teorias e novos problemas, em um ritmo que mal conseguimos acompanhar, como cumprir a promessa de uma preparação para o amanhã? Um amanhã que sequer vislumbramos? Nesse sentido não me parece surpreendente que as novas gerações apresentem desprezo por nossa retórica educacional fundada em bases tão movediças e pouco sólidas como a preparação para o futuro do mundo ou o de cada indivíduo.

Mas, se a preparação para a cidadania não se confunde com a transferência arbitrária de sonhos passados, nem tampouco com a idéia de que cabe à escola ser um serviço social para o êxito econômico individual, qual o sentido de a pensarmos como local socialmente construído para a preparação da cidadania? Parece-me que a relevância da escola como espaço para a preparação da cidadania deriva de ela ser a ponte entre o espaço privado do lar (que diz respeito ao indivíduo e à sua preservação) e o espaço público da sociedade (do que pode ser visto, ouvido e dabatido por todos, que diz respeito ao que é comum entre os homens). E isto fica patente pelo fato de que ainda que a escolaridade possa ser desejada pela família é o Estado que a exige, porque dela necessitamos se quisermos preservar e conservar aquilo que foi pública e abertamente construído.

Assim, à escola cabe um papel de conservação do mundo cultural e científico construído pelos homens em sua atividade pública, ou como destaca Arendt, essa conservação do que o mundo público e comum construiu 
faz parte da essência da atividade educacional, cuja tarefa é sempre abrigar e proteger alguma coisa - a criança contra o mundo, o mundo contra a criança, o novo contra o velho, o velho contra o novo. Mesmo a responsabilidade ampla pelo mundo que é aí assumida implica, é claro, uma atitude conservadora. Mas isso permanece válido apenas no campo da educacão, ou melhor nas relaçðes entre adultos e crianças, não no âmbito da política,(grifos nossos) onde agimos em meio a adultos e com iguais. Tal atitude conservadora em política - aceitando o mundo como ele é...não pode levar senão à destruição, visto que o mundo, tanto no todo como em parte, é irrevogavelmente fadado à ruína pelo tempo, a menos que haja seres humanos determinados a intervir, a alterar, a criar aquilo que é novo (1972, p.242).

O desprezo por esse papel conservador da escola, conservador não em um sentido político, mas no sentido de que ela é uma instituição social de conservação e transmissão dos conteúdos culturais de uma civilização ou nação, tem nos levado a esse equívoco, que se manifesta em termos antagônicos, ora com a ênfase em seu papel econômico para a vida do indivíduo - como se ela fosse uma instituição a serviço do espaço privado - ora com ênfase em interesses políticos ou morais de um segmento particular da sociedade como se ela fosse espaço de um grupo e não do público, daquilo que é comum aos grupos divergentes e mesmo antagônicos que integram uma sociedade. Assim, a idéia do público pressupõe a idéia da divergência e da pluralidade. A decisão de escolarizar ou não a população ou determinados segmentos dela é sempre uma decisão política, assim como a exclusão ou inclusão de determinadas tradições constituintes dessa sociedade no conteúdo consagrado como escolar.

Tomemos como exemplo o ensino da história. Que história ensinar e por qual abordagem? 0 conteúdo histórico que deve nos interessar no âmbito escolar é exclusivamente a história brasileira e européia - fonte da tradição de uma parcela de nossa população - ou deve incluir, por exemplo, a história dos povos africanos e americanos pré-colombianos? $O$ que vem a ser o conhecimento histórico fundamental? Datas, nomes de políticos importantes, mentalidades de povos antepassados, o cotidiano desses povos ou as lutas econômicas dos segmentos sociais? Seguramente não há uma resposta unívoca a essas questões e as escolhas, também neste caso, irão refletir a diversidade própria da cultura como criação da pluralidade do espaço público. Nesta, como em todas as esferas do social, há uma cultura instituída e um movimento instituinte. Construímos socialmente tanto as nossas tradições como suas representações pelo embate público das nossas divergências. E tudo do que aqui foi dito sobre a história aplica-se a quase qualquer outra área do conhecimento. No caso das nossas tradições culturais quanto à saúde, o uso e à fruição de nossos corpos, ou seja, o papel da Educação Física na escola, também poderíamos nos perguntar que formas que compõem nosso legado cultural e teríamos de decidir entre diversas tendências já instituídas e em vias de instituição. Mas, seja qual for o caso, sempre estaremos lidando, escolhendo e transmitindo tradições culturais que nos formaram, conservando aquilo que se constituiu como o saber sistematizado de um povo.

Assim sendo, gostaria de pensar o papel público da escola de 20. grau, seu papel relevante para a formação do cidadão, a partir dessa perspectiva teórica e, sobretudo, a partir dos quase 15 anos que tenho trabalhado com esse segmento da escolaridade. Se voltarmos à citação e às idéias de Rousseau e buscarmos, se não for excessivamente presunçoso, retificá-la, diria que não é papel da escola o desenvolvimento da natureza humana, posto que para isto não se faz necessário o concurso das instituições humanas, bastaria abrigar o aluno e deixá-lo desenvolver-se. À escola, como instituição que preserva e lega às gerações mais jovens o saber acumulado pela cultura do mundo público e comum aos homens, cabe ser a transmissora dessas conquistas intelectuais e culturais de nossos antepassados. Somos, assim, agentes sociais e profissionais portadores de uma tradição e de um saber que remonta a vários séculos, de sociedades que desenvolveram a escrita, a matemática, as ciências, as artes e que nos formaram tal como hoje somos. Somos, portanto, uma ponte entre o passado e o futuro dessas gerações, que encontram um mundo edificado não só no espaço físico e natural, mas também um mundo humano de teorias, explicações e instituições que medeiam nossa existência, nossa condição humana, que supera nossa simples natureza biológica.

Cabe-nos, portanto, uma parte fundamental da preparação para esse mundo comum, que na expressão de Arendt cria algo que, como uma mesa, serve simultaneamente para que nós nos unamos e para evitar que colidamos uns com os outros. E essa preparação não se faz abstratamente, através de máximas ou conselhos de natureza moral, política ou qualquer outra, mas através do contato direto com aquilo que elegemos como os cânones de nossa cultura escolar, com nossos livros, teorias e obras de arte, por exemplo. A justificativa para os conteúdos escolares não repousa, nem deve repousar, na sua possível pertinência ou 
utilidade para um exame vestibular ou para uma revolução qualquer, mas simplesmente no fato de que cabe à escola inserir os jovens nesse mundo que criamos, que se transforma e que será habitado e transformado por eles.

E nesse sentido não há a menor diferença entre o ensino da filosofia, ao qual me tenho dedicado, e o ensino da Educação Física, que na verdade não é simplesmente física, mas cultural. Cada povo, cada cultura inventou e re-inventa formas de representar e de se utilizar o corpo. Jogamos futebol, nadamos e jogamos capoeira porque estamos inseridos em uma cultura que desenvolveu tais capacidades de uso e de fruição dos nossos corpos. Nossos corpos já não mais são mera herança biológica, nossa condição existencial os moldou tal como moldou outros aspectos de nossa existência. O homem que filosofa, que faz poesia, que esculpe, que explica e joga capoeira não é um produto da natureza, mas da condição humana.

Como professores do 20 . grau, não nos cabe simplesmente zelar pela obra da natureza ou pelos interesses dos indivíduos, mas por uma parte importante do elo cultural que nos une aos nossos antepassados e aos nossos contemporâneos. E assim o fazemos através daquela que é nossa atividade específica, que nos distingue dos demais agentes sociais, que é o ensino sistemático dessas tradições e conteúdos escolares que elegemos como representativos de nossa herança cultural. É através desse ensino que apresentaremos as visões e as lutas políticas e morais, entre tantas outras, que marcaram e marcam nossa existência como homens dotados de cultura e inseridos em uma sociedade. $\mathrm{O} 20$. grau é o último estágio dessa educação comum aos jovens, que possibilitaria - ou não - esse elo. O que é uma ótima razão para que nos dediquemos à busca desse elo e resgatemos, assim, a formação não exatamente do homem natural como queria Rousseau, mas do cidadão dotado de uma tradição cultural que possibilita e viabiliza sua inserção e sua ação no mundo.

\section{NOTAS}

1. A epígrafe de Rousseau, extraída da obra Emílio, foi retirada de um artigo de José Mário P. Azanha entitulado $O$ ensino de 2o. grau na Escola de Aplicação da FEUSP, que ao lado do texto A crise da Educação nos EUA, serviu como base para estas reflexões.

2. cf. Hanna Arendt, Entre o passado e o futuro, São Paulo, Perspectiva, 1972.

3. Em um outro escrito, ainda a ser publicado, a respeito da identidade profissional do pedagogo, procuramos demonstrar que a validade desse "slogan" depende da acepção da palavra educação. Se a pensarmos em um sentido muito amplo, sem dúvida é verdadeiro. Virtualmente qualquer instituição social tem um aspecto educativo e ao conviver com os outros aprendemos e ensinamos simultaneamente. Não há homem que não tenha, ao longo de sua vida. ensinado e aprendido de outro homem. Mas dentro do âmbito escolar essa máxima tende a obscurecer a especificidade daqueles que são profissionais da educação. A atividade educacional profissional e institucionalizada na escola pressupõe o ensino, ou seja a transmissão de um conteúdo específico e dentro de um contexto hierarquizado pela posse de determinados conhecimentos e mesmo de um papel social muito diferenciado entre o professor (educador profissional e não eventual) e seus alunos (que eventualmente ensinam a ele ou a qualquer outro algo que sabem).

\section{REFERÊNCIAS BIBLIOGRÁFICAS}

ARENDT, H. A condição humana. Rio de Janeiro, Forense, 1980.

. Entre o passado e o futuro. São Paulo, Perspectiva, 1972.

AZANHA, J.M. Educação: alguns escritos. São Paulo, Nacional, 1987. 